\title{
REINALDO ARENAS: SEM TRÉGUAS COM CLIO
}

Horácio Costa UNAM

Para Nedda e Enrique Anhalt

\section{RESUMO:}

Este ensaio tem como proposta a análise das relações entre literatura e história em El mundo alucinante $e$ Arturo, la estrella más brillante, de Reinaldo Arenas, dois romances que exemplificam as mais importantes alternativas de representação da reflexão histórica da obra do autor. PALAVRAS CHAVE:

Reinaldo Arenas, Literatura, História.

Como gênero literário autônomo que deve tanto à poesia épica como ao romance de cavalaria, o romance moderno sempre constituiu, desde seus albores, um instrumento privilegiado para a reflexão histórica. No início do século XVII, as aventuras dos dois personagens centrais do Quixote, perdidos numa meseta castelhana despovoada e na qual confundem-se imaginário e realidade, só teriam sido possíveis à margem de um Estado sem controle sobre o país que, em princípio, governava; sem dúvida, a concepção mesma de Cervantes das andanças do "Cavaleiro da Triste Figura" acompanhado por seu escudeiro metaforiza, em mais de um nível, a decadência de todo um sistema de coisas, da "coisa" política ibérica em particular. 
Com o Quixote, menciono o momento fundacional na estruturação do romance como instrumento de reflexão histórica. Daquele momento em diante, os romancistas incorporaram todas as transformações do discurso artístico para prosseguir em sua reflexão, segundo diversos pontos de vista ideológicos ou filosóficos, sobre os destinos de seus povos e de cada homem individual no torvelinho dos acontecimentos coletivos. Alternativas estéticas como o realismo, o surrealismo ou o realismo-maravilhoso, o romance de perscrutação psicológica, ou ainda o relato fragmentário e programaticamente intertextual caro aos pósmodernos, nunca deixaram de lado o traço definidor do romance, que é o de conciliar, no mesmo plano de projeção, a reflexão histórica e a imaginação ficcional. Todo romancista contemporâneo sabe que é herdeiro de Cervantes e sabe também que, mesmo que centralize seus esforços criativos à margem ou contrapondo-se à análise histórica, o simples fato de expressar-se através da forma do romance já o situa dentro desta tradição reflexiva.

Mesmo em sentido contrário, Clio, a musa histórica, divindade antes menor mas que soube imprimir sua presença no próprio centro do panteão contemporâneo, insinua seu perfil sobre qualquer discurso romanesco ou com ele aparentado: de maneira mais ou menos evidente, ela reclama o que é seu por direito de costume, pelo uti possedetis, para tanto associando-se, se o considerar necessário, às mais diferentes figuras retóricas, às mais díspares manifestações da linguagem. Assim, habituamo-nos a percebê-la acoplada à alegoria, à metáfora, à paródia; habituamo-nos a identificá-la na collage, na perfomance, $\mathrm{e}$ inclusive nos habituamos a identificá-la mesmo onde parece não estar, como a nuvem dentro da elipse, como elemento de mediação para a intelecção do oxímoro, como a sombra que introduz no presente a fria pulcritude da arte conceitual. Hoje em dia, é uma Clio fortalecida, agigantada, quem parece ocupar o lugar de sua irmã Calíope, patrona da eloqüência e da poesia épica, outrora a primeira entre as musas; ao menos em relação ao gênero literário do romance, esta afirmação parece-me sem dúvida incontestável.

Se todos, ou quase todos, os romancistas reconhecem seu pedigree e, portanto, aceitam como um fato indiscutível a vertente da reflexão histórica em sua escritura, poucos são, entretanto, aqueles que procuram ampliá-la em sua produção romanesca, seja através da análise de processos sociais ou históricos específicos, seja pela reinvenção de novas formas de tratamento desta sua reflexão em suas composições literárias. O romancista cubano Reinaldo Arenas pertencia a esse segundo grupo. Qualquer leitor da extensa obra que o escritor exilado já tinha publicado, quando se suicidou em 1990 em Nova Iorque, não poderá deixar de nela surpreender-se com a quantidade de estratégias textuais seguidas pelo autor para enfrentar a problemática da representação da reflexão histórica na obra de ficção; tampouco poderá deixar de surpreender-se tanto com a precocidade, em sentido etário, da irrupção desta temática em sua obra literária, assim como com a intensidade com que o autor a perseguiu ao longo de seu processo de maturação como escritor. Adiante me ocuparei dos dois romances de Reinaldo Arenas que, sob meu ponto de vista, exemplificam as mais importantes alternativas de representação da reflexão histórica em sua obra. São eles El mundo alucinante, de 1969, e Arturo, la estrella más brillante, de 1984.

No primeiro dos romances mencionados, observamos uma verdadeira plongée dans l'histoire, possibilitada pela estrita associação do "eu" do escritor com um personagem da história real, o religioso e revolucionário novo-hispano Frei Servando Teresa de Mier, um dos forjadores da independência do México durante os primeiros anos do século passado. Numa nota introdutória ao romance, escrita em forma de carta cujo destinatário é o próprio Frei Servando, Arenas declara, aberta e determinadamente, que o frade e ele são "la misma persona". Sua declaração recorda-me a relação de dois romancistas com seus personagens: a de Flaubert, que em sua correspondência privada menciona ser sua genial invenção Emma Bovary, e a de Marguerite Yourcenar com seu Imperador Adriano, cuja voz, habitada por um desconcertante tom de verossimilhança, parece soar página a página no famoso romance que leva o nome deste longínquo césar romano.

Entretanto, a relação de Arenas com seu frade irredento difere num ponto fundamental daquela desses escritores com seus respectivos e mais famosos personagens. Tanto Flaubert como Yourcenar têm o mérito de pôr em cheque o estatuto do gênero sexual na escritura: o primeiro declarando sua ousada "conversão" ao sexo feminino, que teria dado ensejo à concepção da Bovary, ainda que no romance o personagem esteja narrado em terceira pessoa; a segunda pondo em prática uma "conversão"similar, desta feita ao gênero masculino, ao escrever seu romance na primeira pessoa. Através de sua formidável declaração, o que coloca Reinaldo Arenas é uma simbiose meta-temporal, entre criador de personagem de ficção e personagem histórico, como se aquele se convertesse, devido à intensidade de sua plongée dans l'histoire, em alter-ego, na verdadeira versão no presente de uma voz já desvanecida há muito tempo.

Como podemos observar, o gesto de Arenas, mesmo que descartando a subversão do cânon de representação do gênero sexual, que encontramos tanto na declaração de Flaubert como no exercício textual de Yourcenar, junta num 
mesmo plano as posições de ambos os autores: como se Emma Bovary tivesse sido um personagem real e como se Yourcenar tivesse declarado que ela e Adriano eram a mesma pessoa. De passagem, convém mencionar aqui que a escritora belga não esteve longe de afirmar algo afim ao dito por Arenas: no "Carnet de Notes" de seu Adriano, a romancista escreve que sua intenção era "refaire du dedans ce que les archéologues du XIX ${ }^{\text {ime }}$ siècle ont fait du dehors".' Nesta colocação de Marguerite Yourcenar, podemos perceber a relação de sucessão entre historiografia e arqueologia, discursos que, ao menos no século dezenove, queriam-se "objetivos", e romance contemporâneo de inspiração histórica, que assume a subjetividade como uma forma alternativa de compreensão do material histórico: uma noção que, sem dúvida, em seu horizonte ético, coordenou o relacionamento de Reinaldo Arenas com a literatura.

Em termos mais estritamente literários, dois são os recursos que caracterizam a operação textual de El mundo alucinante. Como princípio estrutural básico, observa-se a forte presença no romance da intertextualidade com Apologia, livro de memórias de autoria do monge novo-hispano, no qual Frei Servando narra suas vicissitudes como prisioneiro do Tribunal da Santa Inquisição no México e depois na Espanha, e suas aventuras por meia Europa como advogado da causa da independência do México.

A mecânica intertextual se verifica de duas maneiras no livro: direta, isto é, indiciada no texto do romance por citações com notas ao pé de página, ou indireta, isto é, conservando o texto-base (o de Frei Servando) como "princípio gerador de texto" do romance, tal e qual com razão assinalou Perla Rosencvaig em seu estudo sobre a obra de Reinaldo Arenas. ${ }^{2}$ Depois de sublinhar que "la intertextualidad de El mundo alucinante se palpa y se concretiza desde el principio hasta el fin", a crítica se estende nos seguintes termos sua afirmação:

No sólo se basa en su estrecha relación con las memorias en el plano lingüístico, sino también en la ideología que se filtra mediante el trastocamiento de las secuencias tempóreoespaciales. El lenguaje atrevido y vigoroso que utiliza Arenas transmite el espíritu de lucha y el genio imaginativo del fraile. No hay duda de que el Fray Servando que vive en $E l$ mundo alucinante encarna los ideales del que escribio las memorias. Es la conciencia del texto. ${ }^{3}$

1. YOURCENAR, 1974. p. 319.

2. ROSENCVAIG, 1986. (Especialmente o cop.l).

3. ROSENCVAIG, 1986. p. 17.
Em poucas palavras, Arenas transforma um princípio estrutural, a intertextualidade, em princípio compositivo, com o que quero dizer que uma visão estruturalizadora da obra - a de intertextualização com as memórias de Frei Servando - , desce ao nível mais sensível da linguagem do autor-narrador, que se traveste com o estofo mesmo daquele autor-básico, através da exageração, ou melhor dito, da hiperbolização, da mecânica intertextual, numa atitude francamente mímica, paródica. Aqui, justamente, podemos conservar a segunda característica definidora de $E l$ mundo alucinante: a presença constante da hipérbole e da paródia como os tropos dominantes que informam, de ponta a ponta, a escritura do romance.

Estas duas figuras retóricas, hipérbole e paródia, certamente deixamse entrever no título mesmo do livro. São, como sabemos, selos evidentes dos discursos barroco e neo-barroco. Prefiro não deter-me sobre esse tópico. Simplesmente, quero frisar que é através destes tropos que arenas imprime ao seu texto a pulsação "alucinante": é através da hiperbolização paródica da realidade que o mundo histórico em que viveu Frei Servando, com seus quase incompreensíveis tribunais, convenções, medos e rituais e sua falta absoluta de liberdade individual, se toma perceptivel, tocável e, sob mais de um ângulo, apesar de todo o aparato lingüístico e ficcional surrealizante do discurso, real. Aqui podemos perceber como sua linguagem desbordada se toma crítica da realidade que emascara; porém não apenas da realidade histórica que se encontra na base diegética da obra - por estar, evidentemente, configurada no intertexto de Frei Servando - , mas também de uma realidade histórica mais próxima ao autor e de nós, leitores, no tempo: a realidade cubana que Arenas experimentou. Especialmente nos últimos capítulos de El mundo alucinante, a decepção de Frei Servando com relação ao processo histórico vivido pelo México imediatamente depois de sua independência, caracterizado pelo caudilhismo, pela hipocrisia e pela corrupção dos ideais revolucionários e independentistas, emula, hiperbólica e parodicamente, a decepção de Reinaldo Arenas frente ao processo pós-revolucionário cubano; neste sentido, a continuação do culto guadalupano no México independente sobre as mesmas bases que Servando combatera durante a vigência do estatuto colonial é simbb́lica e encerra o amargo combatera durante a vigência do e monge libertário e seu alter-ego contemporâneo, fundidos numa única voz - frente ao caminho turbulento da história, frente ao alucinatório perfil que Clio reserva para aqueles que dela se aproximam de modo ingênuo e de boa-fé.

El mundo alucinante revelou um autor mais jovem do que se podia inferir pela qualidade textual patente no relato o qual, por sua vez, testemunhava 
de forma indiscutível um talento genuíno para a narração. Ainda assim, este romance apresenta traços de contato com todo o vocabulário retórico e formal do realismo-maravilhoso, apesar das evidentes diferenças ideológicas de Arenas com relação aos nomes de cumeeira deste movimento (especialmente Alejo Carpentier e Gabriel Garcia Márquez). Em Arturo, la estrella más brillante defrontamo-nos com um autor plenamente maduro e mais disposto a afirmar um nível mais pessoal de experimentação literária, sem deixar de lado as conquistas conseguidas em suas obras anteriores. Em seguida mencionarei duas razões para embasar as afirmações que acabo de fazer.

Em primeiro lugar, a concepção mesma do personagem Arturo revela muito da maturidade que Arenas conseguira na época da escritura deste romance. A homossexualidade perseguida de Arturo dá um status mais amplo à crítica de Arenas em relação ao processo pós-revolucionário cubano, transformando seu romance numa defesa e, concomitantemente, numa análise da exceção social. $O$ personagem, encarcerado num dos campos de concentração para a reeducação de homossexuais, piedosamente chamados "UMAPs" "Unidades Militares de Ayuda a la Producción") pelo regime de Fidel Castro, não só é perseguido e maltratado pelos apparátchiki, como também é incompreendido e/ou ignorado pelos mesmos presos que com ele compartilham seu não invejável destino. Arturo é, assim, duplamente rechaçado: pela ordem estabelecida que o encarcera e pela ordem de exceção que constroem os demais presos. Marginalizado pelos donos do poder e pelos próprios marginais, ele é vítima tanto da brutalidade de seus verdugos militares como do desprezo de seus companheiros de cárcere, a "irmandade" frívola e alienada dos demais homossexuais que, ao contrário de Arturo, "podrían ampararse en sus superficialidades, podrían agruparse, chillar, olvidar o no tomar jamás en consideración que desde hacía mucho tiempo ya no se les trataba como a seres humanos."' Como diz o crítico Francisco Soto, a dupla marginalidade e humilhação de Arturo revelam "the sinister ambiguities, the devious and insidious nature of oppression that can resurface and assert itself under different forms and guises." De fato, Arturo, la estrella más brillante erige-se num estudo sobre as origens da opressão e da incomunicação humanas, bem como um amargo documento sobre as alternativas de comportamento individual frente a ambas.

Duplamente acossado, Arturo reage de duas formas diferentes para defender-se. Seu primeiro impulso é de sobrevivência: a mimetização. Imitando

4. ARENAS, 1984. p. 42

5. SOI0. p. 12-16. os modos e o discurso efeminados de seus companheiros de cela, Arturo se converte na "estrella más brillante" da "irmandade", o que lhe garante uma trégua com os demais homossexuais, porém não a almejada preservação de sua subjetividade. Paralelamente, sonha uma arquitetura e um amante imaginários, cuja descrição pormenorizada ocupa espaço crescente no relato. Por outro lado, Arturo escreve furtiva e vigorosamente. Arenas não nos dá a conhecer o conteúdo da esritura de seu personagem até já avançado o romance. Quando o que antes considerávamos como descrição do imaginário do personagem se converte em seu texto e este se confunde plenamente com o do narrador e a alucinação de Arturo é de uma vez por todas predominante no romance, quando percebemos que seu relato é o que lemos, quando definitivamente Arenas cede a palavra, a capacidade autoral, a seu personagem, se dá o desenlace: o fuzilamento de um Arturo totalmente possuído por seu delírio frente ao olhar indiferente dos demais prisioneiros.

Em segundo lugar, sob o ponto de vista estrutural, e retomando em outros termos o anteriormente dito, Arturo, la estrella más brillante está construído como uma espécie híbrida de monólogo interior, no qual alternam narrador e personagem, terceira e primeira pessoas, sem que separem uma voz de outra os sinais diacríticos e a divisão espacial convencionais. Esta mecânica narrativa, como é compreensível, empresta ao romance uma extrema agilidade. A oscilação entre a representação da consciência do personagem e a narração "objetivizadora" por parte do narrador, entra em correspondência com a forma mesma do relato, concebido como um único período sintático, como um fluxo contínuo de informações. Outrossim, essa oscilação, que opera muitas vezes através de cortes abruptos, permite a Arenas obter efeitos dramáticos devido à sobreposição dos registros do devaneio interior de Arturo e da irrupção da realidade oprobriosa na qual o personagem está imerso. Sem dúvida, é essa concepção do relato o que nos permite identificar nele não apenas o mesmo ritmo, mas também a mesma pulsão alucinatória da obra que acima estudamos, ainda que em Arturo, la estrella más brillante a hiperbolização de $E l$ mundo alucinante ceda lugar a uma narrativa tanto menos proliferante quanto mais aguda em sua relação com o imaginário, e mais rica em sua utilização de recursos retóricos e formais.

Se El mundo alucinante é a crônica de uma decepção histórica, Arturo, la estrella más brillante é a rapsódia da inadequação do homem excepcional à ordem histórica. Assim como Frei Servando tenta escapar da História, simbolizada por um Palácio Nacional do México no qual as honrarias rendidas por seus hipócritas admiradores tinham-no prisioneiro, só para encontrar nas 
ruas da cidade a mesma ordem contra a qual ele lutara antes da independência mexicana, o prisioneiro Arturo tenta sua fuga através da imaginação e da escritura, o que o leva a - ou talvez apressa - sua final redenção frente a um radicalmente histórico batalhão de fuzilamento. Num dado momento de Arturo, la estrella más brillante, o narrador diz:

(...) de pronto, reconoció espantado que no había escapatorias, que todos sus esfuerzos habían sido inútiles, y que alí estaban todas las cosas, agresivas, fijas, intolerables, pero reales, allí estaba el tiempo, su tiempo, su generación ofendida y estupidizada, las literas molestísimas y él sobre una de ella, y dentro de poco la voz gritona que le ordenaría incorporarse, integrarse a un terror que ahora, al saberlo definitivo, insuperable, resultaba desde luego aún más espantoso, y pensó, en ese momento, que las pequeñas treguas que por unos instantes se suelen disfrutar casi en cualquier sitio - la sombra de un árbol, la visión de un cuerpo espléndido, la frescura del agua al pasar por la garganta sedienta -, no eran realmente treguas, sino requisitos necesarios que debe observar toda calamidad, toda desgracia, para que quien la padezca pueda establecer diferencias y sufrirla conscientemente, plenamente...

Se Reinaldo Arenas não fez concessões com relação ao destino de seus personagens, Clio, de cujos seios pontudos não jorram o leite e o mel e sim a pólvora e a intolerância, não foi simpática com seu criador. Perseguido em Cuba por dissensão ideológica e por não enquadrar-se, devido à sua opção sexual, à moral "revolucionária", seu árido exílio nos desespiritualizados Estados Unidos não contribuiu para conciliá-lo com a humanidade. Entre Clio e Arenas não existiu trégua, afora os momentos em que o autor, a imagem de Arturo, gozava de "sombra de un árbol, la visión de un cuerpo espléndido, la frescura del agua al pasar por la garganta sedienta": fugazes suspensões no tempo que, se afirmavam sua subjetividade e fortaleciam sua natureza de criador, o levavam a um despertar cada vez mais difícil num mundo regido pela implacável musa histórica.

Em El mundo alucinante e em Arturo, la estrella más brillante existe pelo menos uma mensagem central, uma reflexão básica de Arenas: não se pode escapar da História através da Ficção. Entretanto, ambos os romances são apaixonados exercícios pedagógicos - ou talvez anti-pedagógicos, na medida em que despertam nos leitores uma revisão crítica de certos princípios aos que a "pedagogia", ou o doutrinamento ideológico ou social, os havia acostumado . Os relatos de Arenas, sem abandonar sua natureza básica de fiç̧ão, tornam-se história: escavam em Clio uma veia sensível, talvez façam aflorar uma lágrima ou um sorriso em sua massa pétrea. Ao sensibilizar a musa histórica, ao reclamar a dimensão humana numa divindade que é aparentemente toda hieratismo, a escritura de Reinaldo Arenas cumpre seu destino, sua função: a mesma do romance de sempre.

\section{RESUMEN:}

Este ensayo tiene como propuesta el análisis de las relaciones entre literatura e historia en $\mathrm{El}$ mundo alucinante y Arturo, la estrella más brillante, de Reinaldo Arenas. Estas novelas ejemplifican las más importantes alternativas de representación de la reflexión histórica de la obra del autor. PALABRAS - CLAVE:

\section{Reinaldo Arenas, Literatura, Historia.}

REFERÊHCIAS BIBLIOGRIFICAS

ARENAS, Reinaildo. Aturo, lo estrello mós brillonte. Barcelona: Montesinos, 1984 El mundo olucinonte. México: Diógenes, 1969 (10. ed.). L Lo lomo del ongel. Mólogo: Dodor, 1987.

ROSENCVAIG, Perlo. Reinoldo Arenas: narrotivo de tronsgresión. México: O6́sis, 1986. SOTO, Froncisco. "Reinoldo Arenos's literory legacy". In: Chistopher Sreet. Hovo lorque, n. 156. YOURCENAR, Morguerite. Memoires d'Hodinen. Poris: Gollimord, 1974
REVISTA DE ESTUDOS DE LITERATURA

Belo Horizonte, v. 4, p. 11 - 19, out. 96

TI9 